\title{
Rights in mind: thinking differently about dementia and disability
}

\author{
Abstract \\ The aim of this paper is to argue for the utility of a relational model of disability, as a way of \\ conceptualizing dementia. We explore whether dementia should be considered \\ as a disability, and whether people with dementia might consider themselves as \\ disabled people. We review examples of, and issues raised by, the political activism of \\ people with dementia. We consider how language constructs dementia negatively. We \\ discuss how the environment influences the experience of dementia. In conclusion, we show \\ that a relational model of dementia lays the basis for a human rights approach to the \\ condition, based on collaborative partnerships between people with dementia and people \\ from other disability communities.
}

\section{Keywords}

Human rights, models of disability, environmental barriers, activism

\section{Introduction}

Dementia and disability seem like planets spinning on different axes, their inhabitants aware of each other's existence but apparently unable to communicate (Mittler 2016a). There is a perception in the disability world that dementia is solely a health responsibility. People with dementia do not necessarily think of themselves as disabled. But the planets are aligning. Dementia Alliance International - all of whose members have a medical diagnosis demanded access to the Convention on the Rights of Persons with Disabilities at the WHO's First Ministerial Conference on Dementia (WHO 2015). A strong human-rights based resolution proposed by Alzheimer's Disease International was unanimously approved and later incorporated into the Concluding Call for Action by WHO Director General, Dr Margaret Chan.

Work is now in progress to make a reality of that demand (Dementia Alliance International (2016). Several recent interventions have proposed adopting a social model approach to dementia, borrowing from innovations in disability studies (JRF 2015, MHF 2015). A social model approach distinguishes between the illness/impairment, and the oppression or exclusion that people with the illness/impairment experience. A social model would focus on 
the social barriers faced by people with illnesses and impairments. However, this classic social model approach does not fully account for the complexity of the disability experience (Shakespeare 2006), and so we will argue that it cannot do the required job in terms of dementia. Our suggestion in this paper is that a more innovative approach to dementia is required. This approach must give appropriate weight both to the condition itself, and to the social relations within which people with the condition, and their families, live. Dementia, like disability in general, is a multi-dimensional phenomenon, and requires a response that addresses different aspects, including clinical, psychological, social, and political.

We suggest that regarding dementia as a disability could be beneficial for people living with dementia. As noted by Angus and Bowen-Osborne (2014):

"Disability and illness narratives can provide us with the opportunity to circumvent a reliance on a description of the physical impairment and expose attitudes and practices imposed upon a person..."

We are also interested in whether categorizing dementia as a disability may help us to explore some of the ways that barriers and discourses shape experiences of the condition. Perhaps most importantly, we hypothesize that seeing dementia as a disability could place people with dementia, as self-advocates, at the centre of their own stories, and help provide an enabling identity.

\section{Dementia as disability}

We need to start by asking whether or not dementia is a disability (or impairment, to use social model language, see Oliver 1990). This is different from the question of whether people with dementia consider themselves disabled. The first question can be answered more or less objectively, the second question is subjective, depending on the attitudes, values and experiences of individual people with dementia themselves.

The WHO International Classification of Functioning, Disability and Health defines disability as "an umbrella term for impairments, activity limitations and participation restrictions" (WHO, 2002, 2), referring to the negative aspects of the interaction between an individual with a health condition and that individual's contextual factors (environmental and 
personal factors):

According to Article 1 of the UN Convention on the Rights of Persons with Disabilities (CRPD):

"Persons with disabilities include those who have long-term physical, mental, intellectual or sensory impairments which in interaction with various barriers may hinder their full and effective participation in society on an equal basis with others."

In UK law, the Equality Act 2010 states that a person (P) has a disability if:

(a) P has a physical or mental impairment, and

(b) the impairment has a substantial and long-term adverse effect on P's ability to carry out normal day-to-day activities.

In general terms, the dementia syndrome is characterized by progressive decline in cognition of sufficient severity to interfere with activities of daily living (Knopman et al., 2001). Therefore, dementia may be seen as having the features of a disability, in the same way as with other degenerative conditions such as Huntington's disease, multiple sclerosis or Parkinson's disease. The fact that a specific disease or syndrome - such as Alzheimer's - is hard to diagnose and define does not negate this. Other health conditions, such as schizophrenia or autism, are equally complex, and yet it is clear to most observers that they can be usefully regarded as disabilities because they are associated with difficulties in functioning. Epidemiologists generally categorise dementia among the wider category of disabilities (ADI and WHO 2012, 8; Stephan and Brayne, 2010:14; WHO 2003). So we would argue, that from semantic, epidemiological and legal perspectives, dementia is a disability.

The answer to the second question, concerning whether people with dementia think of themselves as disabled, will always be provisional. As with the co-author of this paper, some people living with early-stage dementia have strongly articulated a disability identification; some are reluctant to do so; others are silent (Whitman 2015). Many will reject what they may perceive as another stigmatising label.

However, this is not very different from people with other impairments. A study carried out 
for the Department for Work and Pensions found that $52 \%$ of people with rights under the Disability Discrimination Act did not identify as disabled (DWP 2002). Many people with learning difficulties are reluctant to adopt the label disabled, as are many Deaf people (Shakespeare 2006). Older people, who make up around half of all disabled people, can view their functional deficits as part of normal ageing, and hence are less likely to identify as disabled (Kelley-Moore et al 2006). We can anticipate that people with dementia will also vary in their willingness to identify as disabled. But like other groups, they can still use the UN Convention on the Rights of Persons with Disabilities (CRPD) as a tool to advance their rights.

Certainly, people with dementia are not seen by the general public, professionals or by other disabled people as part of the disability rights community. The dementia community has never been part of the disability movement, and did not join forces with the powerful coalition of disabled people's organisations which campaigned for the Convention (Sabatello and Schulze 2014). This is the paradox that we are seeking to address in this paper.

Dementia is a decrement in functioning (WHO 2001), but the corollary that people with dementia are disabled is harder to accept. If people with dementia are a specific group, then they have rights and an ability to articulate their own needs (Taylor 2007, Swaffer 2016). This was clearly articulated by Marshall some 16 years ago (as noted by Gilliard et al, 2005: 576) arguing for the positive benefits of regarding dementia as a disability. We recognise the danger of subsuming all people with dementia (who are innately diverse and who are affected differently) into one group, let alone into the wider disability community. But forming a unitary movement was no less challenging for people with mental health conditions (Wallcraft and Bryant 2003).

\section{More than a medical condition}

The banner under which other disability communities have united is opposition to inappropriate medicalization. The point about the social model of disability is that it distinguishes between the health condition, on the one foot, and the social experience of exclusion, on the other. However, dementia still remains trapped within the dominant medical discourse.

Since the late 1990s, there has been a slow but steady movement away from the 
tendency to view dementia solely within a medical framework (Ballenger, 2006, Basting, 2009, Killick, 2013, Kitwood, 1997, Sabat, 2014). Kitwood's notion (1990) of "malignant social psychology" was perhaps the seminal conceptualization provoking a reconsideration of the role of social environment for people with dementia. Reliance on a solely medical framework has been increasingly criticised for maintaining the exclusion and passive dependency of people with dementia:

'It is important .... to identify correctly what constitutes a symptom of neuropathology as opposed to an appropriate emotional reaction to an extremely undesirable situation or to dysfunctional social treatment.' (Sabat, 2008:71). In both research and policy, an increased understanding of the ways in which social dimensions can be influential (positively and negatively) has helped re-focus dementia research on the person, rather than solely the illness (Gilliard et al 2005).

Practice has been slower to change. In 2015, the OECD stated that dementia receives "the worst quality of care in the developed world" (OECD 2015). But there is an increasing focus on improving quality of life for people with dementia (Gross, Danilova et al. 2013), including the social conditions in which people live, whether in care homes or in the community (Dodd and Bush 2013). The importance of investigating 'nonpharmacologic tools' has also been widely embraced across the US (Kaldy 2013).

Pioneering work by researchers and practitioners has contributed to the understanding that although Alzheimer's and other dementias may be incurable at present, they are conditions that can be treated. While antipsychotics may work for some people, treatment always includes more than drugs and requires attention to the social environment in which people with dementia live (Kitwood 1997, Sabat 2001, Zeisel 2009, Killick 2013). WHO promotes a model of Healthy Ageing, which takes the environment into account, not just intrinsic capacity (WHO 2016).

Nevertheless, medicalisation still predominates. This is partly a product of biomedical models of illness that can be traced back to the Enlightenment (Bond, 2001). One consequence of the medicalization of dementia is the way in which disease is seen as the loss of 'normality' with the associated labelling of people with dementia as 'victims' or 'sufferers' (Bond 2001: 45). An important influence is the financial dominance of 
pharmaceutical companies, which are primarily concerned with the huge market in drugs for these conditions (Moynihan and Cassels, 2006). The tendency to over-medicalise dementia, and people with dementia, has obscured the importance of social conditions that contribute to disabling people with the condition.

\section{People with dementia are activists too}

One factor that may account for the continued over-medicalisation is the relatively recent emergence of dementia activism. Political action by people with mental health problems, physical impairments and those affected by HIV/AIDS (Wallcraft and Bryant 2003, Campbell and Oliver 1996, Hughes 2009) has redefined these issues. Unlike the disability movement, whose sustained advocacy led to the UN Convention, (Mittler 2016b) those with dementia have only recently started to unite and attempt to influence policy. As noted by Bartlett:

"Dementia activism is a newly emergent phenomenon ..... With few exceptions, activism by people with dementia has not been the prime focus of research." (Bartlett 2014a, $624)$.

The novelty of dementia activism reflects the assumption that the rapid progression of the illness means that individuals do not have the capacity to make speeches or campaign. The trend for earlier diagnoses, and the work of groups such as the Scottish Dementia Working Group and the Dementia Engagement and Empowerment Project (DEEP 2016) have demonstrated how those with dementia can effectively unite and advocate.

At the international level, Dementia Alliance International (www.infodai.org ) has led the campaign for access to CRPD. For example, it has recently succeeded in persuading Alzheimer's Disease International to adopt a human-rights-based policy which includes making full use of the UN Convention on the Rights of Persons with Disabilities and has submitted its own report to a UN General Day of Discussion on Independent Living and Participation in the Community (Mittler 2016c). DAI has facilitated exchange and discussion among people with dementia. For example, a persistent theme raised in DAI writings and blogs is the 'prescribed disengagement' (Swaffer 2016) that accompanies diagnosis, with 
advice to the patient to stop work, hand in their driving license and prepare for an early death. Another is the social isolation that follows disclosure of diagnosis when friends, neighbours and family members deliberately avoid meeting them (Taylor 2009).

The human rights based approach (HRBA) is based on participation of people with lived experience, as with the disability rights movement's motto 'nothing about us without us'. Yet there is a shocking lack of consultation with people with dementia throughout much of dementia care (Gilliard et al, 2005).

Self-advocacy is not straightforward in the case of dementia. Only those with mild to moderate impairment are able to advocate for themselves or their peers, even with support (Karlsson et al 2014). In addition, dementia activism can be exhausting (Bartlett 2014b). The short lifespan of the publication 'The Voices of Dementia", a US journal of and by individuals living with the symptoms of dementia, shows that continuity can be precarious.

Terry Pratchett is a pertinent example of one well known UK dementia activist. He was articulate about the effects of dementia, vociferous about the need for further funding and better understanding about living well with the 'embuggeration' that is dementia:

"I regarded finding I had a form of Alzheimer's as an insult, and I decided to do my best to marshal any kind of forces that I could against this wretched disease." (Pratchett 2015)

Yet Pratchett was only able to be an activist for eight years. Nevertheless, Pratchett lived longer with dementia than average. The brief life-span of those with dementia (it has been estimated that on average men live for 4.1 years and women live for 4.6 years following onset of dementia, (Xie, Brayne \& Matthews, 2008)), makes it difficult for long-term change to be achieved. As Bartlett (2014a) has convincingly outlined, 'temporality' is a distinctive feature of dementia activism. This is partly because of the degenerative nature of the illness, but also because the temporal structure of the condition is so perplexing. Campaigning within more established disability rights networks may help dementia activism have a sustained impact. Echoing the movement of people with learning difficulties, where supporters and advocates add weight to the voice of lived experience, is another approach (Roberts et al 2012). 


\section{Towards a relational model of dementia}

Interest in the social conditions that affect dementia reflects the burgeoning of community-based initiatives for people living with a dementia. There has been a general movement away from formal spaces designated for care and support toward a more diffuse range of community-based spaces that are both accessible to and supportive of people with dementia. In this context the policy-driven notion of Dementia Friendly Communities (Prime Minister's Challenge on Dementia 2012) and campaigns such as 'Dementia Friends' might be understood as reflecting this effort to re-think both the place of care and the ascription of responsibility to provide care and support.

So far, social responses to dementia have centered on the need for awareness. In some ways, this echoes the early stages of disability politics. Yet "awareness" and "friends" are rather weak concepts. We argue that what is required is a stronger response, an equalitiesbased approach, that recognizes that people with dementia are a minority group in society, who are poorly served in many environments, and who consequently face exclusion, even oppression.

In several recent papers (Mental Health Foundation 2015, Thomas and Milligan 2015), attempts have been made to outline a social model of dementia. There is much sense in these papers, and they are to be welcomed. They are genuinely committed to fresh thinking about the experience and response to dementia, and to the empowerment of people who live with this condition. However, at the same time, we believe they miss opportunities to outline how a social relational approach can be applied to dementia, because their understanding of disability remains crude.

The original Union of Physically Impaired Against Segregation (UPIAS) (1976) model of disability, labelled the social model and elaborated by Michael Oliver (1990), distinguishes between impairment (medical) and disability (social), and focuses on social barriers and oppression. It has been criticized for reducing the complexity of disability to crude environmental determinism, and for ignoring the personal experiences of those living with illness and impairment (Morris 1991, Shakespeare 2006). Because the social model was developed to account for the experience of people with static physical impairments, it fails adequately to contextualise impairments which are associated with pain; with limitation; with frailty; and with degeneration. Despite the best efforts of Carol Thomas (1999, 2007), the 
social model approach has also failed to make adequate space for psychological issues. Dementia highlights again how the social model has are never been very good at conceptualizing cognitive impairments (Chappell 1998) or mental health conditions (Beresford 2012).

How do attitudes, environments, and policies make life harder for people with dementia (and their families)? How can inclusion be achieved? The Mental Health Foundation paper states this social model aim clearly:

"A social model approach argues that people with dementia must be viewed as a legitimate part of mainstream society, living in communities as equal citizens with their value recognized and respected" (MHF 2015, 21).

However, it does not fully engage with the implications of this position. 'Dementia Friendly Communities' are not enough. People with dementia have lived independently and been fully participating members of their community all their lives but encounter deep-rooted and systemic attitudinal and societal obstacles to continuing to do so following diagnosis. Even a phrase like 'dementia friendly', while apparently positive, could be considered patronizing and inappropriate. The implication is that the solution to the dementia problem is for people without dementia to be kind and welcoming of people with dementia. But if the problem includes socially-imposed barriers, devaluing and even human rights violations, then the term 'friendly' might be judged an inappropriate response. which we would not use for other excluded groups. As Kate Swaffer has said, we might ask instead for 'Dementia Enabling Communities'. Long-term disability activist Ian Popperwell writes in his blog:

"Subtle courtesies and acts of kindness can make all the difference to how any of us experience our worlds, but for me there is an ugly flavour of charitable patronage when the term 'friendliness' is used instead of the carefully tried and tested words that speak much more of rights, dignity, consistency and thoughtfulness.” (Popperwell 2014).

A more inclusive social model approach would ask: do mainstream services (health, transport, housing) place barriers in the way of people with dementia? Do people receive equal treatment? Is there 'reasonable adjustment' to the needs of people with dementia? For 
example, people with dementia do not have their non-dementia health needs adequately dealt with by the health service (see Alzheimer's Society report 'Fix Dementia Care' 2016). This has also been found to be the case for people with learning disabilities and people with mental health conditions (e.g. Melville et al 2006). In response, doctors and receptionists and others would need to change their ways of working to ensure that people with dementia get screened for cancer, or get their flu immunization, or get referred for investigations when they present with other symptoms, or get treated well in hospitals.

Moreover, a universal design philosophy, with an emphasis on barrier removal in physical environments and also in information provision, would provide an overall context for the many ongoing efforts to create more inclusive environments for people with dementia. However, going further than universal design, it would be desirable to provide more supportive responses to ensure that people with dementia feel welcome and included (Nuffield Council on Bioethics 2009). There is evidence that unsupportive environments can contribute to anxiety and agitation for people with dementia (Chaudhury \& Cooke, 2014:144). One relevant initiative is the Personal Assistant Dementia (PAD) role which operates in Walsall. Individuals provide information, support, and signposting to people in the first three months after diagnosis.

Due to marketisation, increasing consumer choice and our growing reliance on online interactions, the world has arguably become more confusing for everyone, and particularly for people with dementia as they seek to engage with services in the public and private sector. For example, technologies like mobile phones and services such as banking are very complex, demanding passwords and interactions that may exclude or disable people with dementia (Nygard and Starkhammar 2007, Batchelor et al 2012). Yet technology could and should enable people with dementia (Lauriks et al 2007, Wherton and Monk 2008). For example, in response to this socially engendered disabling, the simple-to-use Raku phone has been developed in Japan.

In the classic case of mobility impairments, the disabling environment is very obvious (e.g. lack of ramps and accessible bathrooms) and the solutions are clear. If an environment is rendered accessible, and discrimination is effectively countered through education or legislation, then people who use wheelchairs can participate on an equal basis with others. The solutions are more complex for someone who lacks 
or is losing cognitive ability'; whose fluctuating mental health condition means that for days at a time, s/he is unable to get out of bed or interact with others at work; or a person on the autistic spectrum who experiences neurodiversity. Full equality for people with dementia may be elusive, but creatively inclusive responses are long overdue.

A statement such as "The medical model maintains oppression, exclusive and passive dependency of the person" (MHF 2015, 14) is a simplification of a very complex process whereby a person with dementia ends up being treated as dependent and denied a voice. Perhaps a better extrapolation of what happens when someone has dementia is that she is viewed in terms of her inabilities, whether these are cognitive, relational or functional, and in comparison to an expected norm of personhood. Her strengths become invisible. Her emotional and social bonds stand for nothing. Her disease and difficulties become her defining features. On top of her diagnosis, a heavy weight of negative cultural representation (Peel 2014, Zeilig 2014) clouds the collective vision of this person living with dementia.

A relational disability model of dementia would take an adequate and nuanced approach to dementia whereby there was both medical research into deficits and treatments, and action to remove social, attitudinal and architectural barriers. Similarly, empowering people with dementia as far as possible is clearly an important goal, but policy should also recognize that people with dementia will require support and protection when their disease makes it impossible for them to be active. The Mental Health Foundation paper refers to this approach which 'gives greater credence to the personal experience of having a disability, in conjunction with the political and social contexts' (MHF 2015, 15). This is seen as an appropriate approach, given that "the majority of people with dementia frame dementia as an illness or disease" and that the "disabling factor may be intrinsic to the condition". The author(s) conclude by saying "the social model needs to take account not only of the external barriers, but also of the social and psychological obstacles that exclude or restrict full participation in society" (MHF 2015, 15).

This approach would look at how both the health condition itself, and the social responses to it, generate the disability (Shakespeare 2006). Such an approach could be conceived in terms of the International Classification of Functioning, Disability and Health (ICF) (WHO 2001), where disability arises from the interaction of a health condition with environmental factors 
and personal factors. Alternatively, various scholars have proposed a critical realist approach to disability (Dannermark and Gellerstedt 2004, Shakespeare 2006), entailing a laminated model. This refers to the different levels - the biological, the psychological, the environmental, the social, the legal - which interact to produce the experience of disability. We believe this could offer a more adequate understanding of the complexity of dementia.

\section{Dementia as a human rights issue}

The corollary of regarding dementia as a form of disability, and articulating either a social or relational disability model of dementia, is that dementia should be regarded as a human rights issue. At the domestic UK level, this means the Equality Act, and at the international level the equivalent is the Convention on the Rights of Persons with Disabilities (CRPD), which the UK ratified in 2009. As the Mental Health Foundation (2015), Neil Crowther (2016), Peter Mittler (2016a, 2016b) and others have argued, it is long overdue for the CRPD to be applied to, and used by, the dementia community. It is frequently said that the CRPD uses a social model of disability. Article 1 talks about the interaction of impairments with various barriers. Rather than a traditional social model, this would be better interpreted as endorsing the relational approach discussed above. In other words, both the impairment and the barriers, interacting together, hinder full and effective participation in society.

The CRPD offers benefits to people diagnosed with dementia, in particular Article 12, which states that people with disabilities have legal capacity on an equal basis with others. Status-based approaches to capacity are discriminatory: rather than taking away someone's driving license when they are diagnosed, it should depend on independent assessment of capacity to drive, i.e. a functional approach to capacity. Article 12 promotes supported, rather than substitute, decision making, which could be a beneficial process in dementia. Rather than automatic guardianship as soon as someone shows signs of cognitive impairment, the principle of "supported decision making" entails working with the individual to ascertain their will and preference. Yet dementia also challenges Article 12. The Essex Autonomy Project (2014) and many psychiatrists, philosophers and lawyers (e.g. Freeman et al 2015, Dawson 2015) have found the wording and implications of Article 12 and its radical interpretations very hard to elucidate or implement practically. Nuffield Council on Bioethics (2009) and others have stressed instead "joint decision-making" with trusted family or friends. 
A second area in which dementia - and other complex conditions - challenges the CRPD concerns the role of the family and other informal carers of people with dementia. Carers also share the lived experience of dementia. Most importantly, they provide the vast majority of support and assistance for people living with dementia (Nuffield Council on Bioethics 2009). Family members are largely absent from the CRPD, aside from an explicit mention in the Preamble and implicitly in in Article 23, 'Respect for home and family'. The absence of family members or other third parties reminds us that a human rights approach is essentially individualistic. An individual makes a claim because their rights are violated. Yet people live their lives relationally. In every state, including the wealthiest, informal carers provide the majority of assistance (WHO 2011). To the extent that it fails to engage with the experiences of people with dementia - or indeed profound intellectual disabilities - the Convention on the Rights of Persons with Disabilities promotes the liberal individualist fiction, rather than the complex, messy, interdependent reality of life.

\section{Conclusion}

Bringing dementia within the disability rights mainstream is not easy._The usual language of disability rights is hard to apply. What would "Dementia Pride" mean, for example? There may be no world in which it would be easy to have dementia (or Motor Neurone Disease or Parkinson's), but there should be a world in which it is possible to live better with these conditions. Hence the emphasis on Living Well with Dementia (Swaffer 2016) or Living Beyond Dementia.

As with other areas of disability politics, there is a danger of a Pollyanna-ish approach, which overlooks the unpleasant and difficult aspects of having an illness or impairment (Carel 2008). That is why taking dementia seriously means reconfiguring our approaches to disability as a whole. The condition of dementia challenges the disability community to remember how impairments can impact daily living, and how emotionality is important. It also reminds us how humans can communicate and connect without language, and that we are more than our memories (Basting 2009, Banner 2014). As noted by the activist Richard Taylor:

"It is true that I am fundamentally different from you. I am different in ways I can't express and you can't fully perceive or understand. Our brains are different. But I am 
still a complete human being”. (Taylor, 2011)

Here Taylor asserts both his status as 'different' and also his fundamental completeness and thus similarity to all human beings. Dementia highlights the diversity of disability. We often speak as if there is one shared disability experience. We talk of disabled people, which implies a unity. Yet there are many experiences. Impairments and illness differ in the way they affect people, and the extent to which they affect people. There is a particular distinction between impairments that are physical or sensory, and those that have a cognitive dimension: people with learning difficulties and people with mental illness are more excluded. We argue that people with dementia are among the most excluded, by virtue of the loss of experience and relationships which they have enjoyed throughout their lives.

The work of Killick (2014), Hughes (2013), Sabat (2008) attests to the possibility that people with dementia can maintain reciprocal relationships, even at fairly advanced stages of the illness, and confirm the persistence of relationality. This sense of 'being with others' (a concept borrowed from the philosopher Heidegger), the cultural and social exchange and sharing that continues for people with dementia, is perhaps the strongest indication that personhood and identity are not destroyed by dementia. If we are beginning to understand the voice that people with dementia retain, and the possibilities for a more expanded understanding of personhood, then we open the doors to a more powerful articulation of the rights of people with dementia and thus their ability to retain their humanity to the end of their lives.

We have argued here that it is vital to situate the individual experience of dementia in the broader social context. We also need to articulate a human rights perspective in which selfadvocacy is core. We need to expand our ideas about social models and about human rights in order to incorporate the experience of all human beings, including people living with dementia. We are embarking on a project of cultural transformation (Scully 2012, 72).

Seeing dementia as a disability, within whatever version of the social or laminated model you choose, might be very helpful for people with this condition. But it is unclear at the moment how it could be operationalised. We lack sufficient consistent work inclusive of people with dementia, and activism of people with dementia themselves over a period of time. This paper has been a collaboration between a disabled person, a person with a mental health condition, 
and a person living with dementia. Our combined experiences of living with disability has added depth to our understanding, both at the level of lived experience and intellectual endeavour. The politics of dementia demands that people with and without the condition work together. Understanding the experience of dementia means incorporating the psychological and the cultural and the structural with the medical. This is a complex enterprise.

As a society, if we can assimilate and acknowledge all that dementia implies, and the diverse ways in which people with dementia want to live, then we will also have a more profound understanding of life, and all that it entails - not just decay, loss, transience and difficulty, but also joy, love and friendship. The benefits will be felt not just by those living with dementia, but by people living with disability - and indeed, everyone.

\section{Declaration of competing interests}

The authors declare that there is no conflict of interest. 


\section{References}

Alzheimers Disease International and World Health Organisation (2012) Dementia: A Public Health Priority. Geneva: WHO.

Alzheimer's Society (2016) Fix Dementia Care: Hospitals, Alzheimer's Society, London.

Angus, J. and Bowen-Osborne, S. (2014) A self narrative of life-long disability: A reflection on resilience and living with dementia. Dementia 13(2) 147-159.

Ballenger, J. (2006). Self, senility, and Alzheimer's Disease in Modern America: A History. Baltimore, John Hopkins University Press.

Banner M (2014) Dying and 'death before death': on hospices, euthanasia, Alzheimer's, and on (not) knowing how to dwindle, Chapter 5 in The Ethics of Everyday Life: moral theology, social anthropology, Oxford: Oxford University: 107-134.

Banerjee, S. (2009). The use of antipsychotic medication for people with dementia: time for action. A Report for the Minister of State for Care Services. London: Department of Health

Bartlett, R. (2014a) The emergent modes of dementia activism. Ageing and Society 34(4) 623-644.

Bartlett R (2014b) Citizenship in action: the lived experiences of citizens with dementia who campaign for social change, Disability and Society 29, 8: 1291-1304

Basting, A. D. (2009). Forget memory: creating better lives for people with dementia. Baltimore, Johns Hopkins University Press.

Batchelor R, Bobrowicz A, Mackenzie R, Milne A (2012) Challenges of ethical and legal responsibilities when technologies' uses and users change: social networking sites, decision-making capacity and dementia, Ethics of Information Technology 14: 99-108 
Bender, M.P. \& Cheston, R. (1997) Inhabitants of a lost kingdom: a model of the subjective experiences of dementia. Ageing and Society, 17(5): 513-32.

Beresford P. (2012) Psychiatric system survivors: an emerging movement. In N.Watson, A.Roulstone and C.Thomas (eds) Routledge Handbook of Disability Studies. Routledge, London, pp. 151-164.

Bond, J. (2001) Sociological Perspectives. Chapter 3 pp.44- 61 in Cantley, C. (ed) A Handbook of Dementia Care. Buckingham: Open University Press

Burke, L (2007) 'The Poetry of Dementia: Art, Ethics, and Alzheimer's disease in Tony Harrison's Black Daisies for the Bride' in Journal of Literary Disability 1.1, pp.61-73

Burke, L. (2008) 'The Country of My Disease: Genes and Genealogy in Alzheimer's Life writing' in Journal of Literary and Cultural Disability Studies Volume 2, Number 1 / May 2008, pp.63-74

Burke, L. (2014), 'Oneself as Another: Intersubjectivity and Ethics in Alzheimer's illness narratives' in special issue, 'Narrative Emotions and the Shaping(s) of Identity', Narrative Works, Fall, Volume 4. Number 2. https://journals.lib.unb.ca/index.php/NW/article/view/22781. Date accessed: 22 Sep. 2015

Burke, L. and Zeilig, H. (2015) Dementia: Ways of Talking. Conference presentation for British Society of Gerontology: Newcastle (02/07/2015)

Caddell, L.S. \& Clare, L. (2011) Studying the Self in people with dementia: How might we proceed? Dementia 12(2): 192-209.

Campbell J and Oliver M (1996) Disability Politics: Understanding Our Past, Changing Our Future, London: Routledge.

Carell, H. (2008). Illness: the cry of the flesh, Routledge: London.

Chappell, A. (1998) Still out in the cold: people with learning difficulties and the social 
model of disability, in T.Shakespeare (ed) The Disability Reader, London: Cassell, pp 211220.

Chaudhury, H. \& Cooke, H. (2014). Design matters in dementia care: the role of the physical environment in dementia care settings. Chapter 11: 144-158 in Excellence in Dementia Care: Research into Practice. M. Downs and B. Bowers. Buckingham: Open University Press

Crowther, N. (2015). Dementia, human rights and the social model of disability (https://makingrightsmakesense.wordpress.com/2015/09/28/dementiahumanrights-and-the-social-model-of-disability/ (Consulted May 5 2016)

Danermark B., Gellerstedt L.C. (2004) .Social justice: redistribution and recognition - a non-reductionist perspective on disability, Disability and Society, $19,4,339-353$

Dawson, J. (2015). A realistic approach to assessing mental health laws' compliance with the UNCRPD, International Journal of Law and Psychiatry 40: 70-79

Degener, T. (2016) A human rights model of disability" in: Peter Blanck \& Eilionoir Flynn (eds.) Routledge Handbook of Disability Law and Human Rights. London, New York: Taylor \& Francis, pp. $31-50$

Department for Work and Pensions (2002). Disabled for Life? Attitudes towards and experiences of, disability in Britain, Leeds: HMSO.

Dementia Alliance International (2016) The Human Rights of People Living with Dementia: From Rhetoric to Reality. www.dementiaallianceinternational.org (Consulted November 8 2016)

Dementia Engagement and Empowerment Project (2016) Our Dementia, Our Rights. Exeter: www.innovationsindementia.org Consulted $8^{\text {th }}$ November 2016.

Dodd, K. and Bush, A. (2013). Quality Outcome Measure for Individuals with Dementia 
(http://www.learningdisabilityanddementia.org/uploads/1/1/5/8/11581920/qomid_ final_jan_2013.pdf Consulted May 5 2016)

Essex Autonomy Project (2014). EAP response to UNCRPD General Comment. http://autonomy.essex.ac.uk/eap-response-to-uncrpd-draft-general-comment (Consulted 3 May 2016)

Equality Act (2010) found at http://www.legislation.gov.uk/ukpga/2010/15/contents (Accessed 20 March 2016)

Ferrie, J. and Watson, N. (2014). The psycho-social impact of impairment: The case of motor neurone disease. In T.Shakespeare (ed) Disability Research Today: international perspectives, Routledge: London.

Freeman MC, Kolappa K, de Almedia JMC, Kleinman A, Makhashvili N, Phakathi S, Saraceno B, Thornicroft G (2015). Reversing hard won victories in the name of human rights: a critique of the General Comment on Article 12 of the UN Convention on the Rights of Persons with Disabilities, The Lancet Psychiatry 2, 9: 844-850

Gilliard, J., Means, R., Beattie and A., Daker-White, G. (2005). Dementia care in England and the social model of disability. Dementia 4, 4: 571-586

Goyder, J., Orrell, M., Wenborn, J. and Spector, A. (2012). Staff training using star: a pilot study in UK care-homes. International Psychogeriatrics 24 (6) 911-20.

Gross, S. M., Danilova, D., Vandehey, M. A. \& Diekhoff, G. M. (2013). Creativity and dementia: Does artistic activity affect well-being beyond the art class? Dementia doi: $10.1177 / 1471301213488899$

Karlsson E, Sävenstedt, Axelsson K, Zingmark K (2014). Stories about life narrated by people with Alzheimer's Disease, Journal of Advanced Nursing 70 (12) 2791-2799.

Herskovits, E. (1995). Struggling over Subjectivity: Debates about the "Self" and Alzheimer's Disease in Medical Anthropology Quarterly, New Series, 9 (2) Cultural 
Contexts of Aging and Health, (Jun., 1995): 146-164.

Hughes B. (2009). Disability activisms: social model stalwarts and biological citizens. Disability and Society 24 (6): 677-688

Hughes, J. (2014). How we think about Dementia: Personhood, Rights, Ethics, the Arts and what they mean for care. London: Jessica Kingsley Press.

Kaldy, J. (2013). Alternative therapies for a new era of health care. The Consultant Pharmacist 28(2): 84-90.

Karlsson, E., Savenstedt, DR., Axelsson, K., Zingmark, K. (2014). Stories about life narrated by people with Alzheimer's disease. Journal of Advanced Nursing, 70(12) pp.2791-2799.

Kelley-Moore JA, Schumacher JG, Kahana E, Kahana B (2006). When do older adults become "disabled"? Social and health antecedents of perceived disability in a panel study of the oldest old. J Health Soc Behav 47(2): 126-141

Killick, J. (2013). Dementia Positive. Edinburgh: Luath Press Ltd.

Kitwood, T. (1997). Dementia Reconsidered: The Person Comes First. Maidenhead, Open University Press.

Kitwood, T. (1990). The dialectics of dementia: With particular reference to Alzheimer's Disease. Ageing and Society, 10(2): 177-96

Knopman, D., S. T. DeKosky, J. Cummings, H. Chui, J. Corey-Bloom and J. Stevens (2001). Practice parameter: diagnosis of dementia: an evidence-based review. Report of the quality standards committee of the American Academy of Neurology. Neurology 56(9): 1143-1153.

Lauriks SI, Reinersmann A, Van der Roest HG, Meiland FJ, Davies RJ, Moelaert F, Mulvenna MD, Nugent CD, Dröes RM. (2007). Review of ICT-based services for identified 
unmet needs in people with dementia. Ageing Research Reviews 6(3) 223-46.

Melville CA, Cooper SA, Morrison J, Finlayson J, Allan L, Robinson N, Burns E, Martin G (2006). The outcomes of an intervention study to reduce the barriers experienced by people with intellectual disabilities accessing primary health care services, Journal of Intellectual Disability Research 50(1): 11-17.

Mental Health Foundation (2015). Dementia, rights and the social model of disability, Policy discussion paper, London, Mental Health Foundation.

Mittler P (2016a). The United Nations Convention on the Rights of Persons with Disabilities: What Does It Have to Offer People with Dementia? Paper presented at Health Policy Plenary, Annual Conference Alzheimer's Disease International, Budapest, April 23rd.

Mittler P (2016b). The UN Convention on the Rights of Persons with Disabilities: implementing a paradigm shift, in Iriarte E, McConkey R, Gilligan R (eds) Disability in a Global Age: a human rights based approach, Basingstoke, Palgrave Macmillan.

Mittler, P (2016c). The right of persons living with dementia to be supported to live independently in the community. Dementia Alliance International Position Paper to UN Day of General Discussion on CRPD Article 19. Geneva, April 19th 2016. http://www.ohchr.org/EN/HRBodies/CRPD/Pages/CallDGDtoliveindependently.aspx

Morris, J. (1991). Pride Against Prejudice. London: Women's Press

Moynihan, R. and Cassels, A. (2006). Selling Sickness: how the world's biggest pharmaceutical companies are turning us all into patients. New York: Nation Books.

Nuffield Council on Bioethics (2009). Dementia: ethical issues, London: Nuffield Council on Bioethics.

Nygård and Starkhammer S (2007) The use of everyday technology by people with dementia living alone: mapping out the difficulties, Aging and Mental Health, 11, 2: 144- 
Organisation for Economic Co-operation and Development (OECD) (2015). Addressing Dementia: The OECD response. Paris: OECD

Oliver, M. (1990). The Politics of Disablement, Basingstoke, Macmillan.

Peel, E. (2014). The living death of Alzheimer's' versus 'Take a walk to keep dementia at bay': representations of dementia in print media and carer discourse. Sociology of Health and Illness 36,6: 885-901

Popperwell, I. (2014). Are dementia-friendly communities the best we can hope for? http://ianpopperwell.com/2014/06/12/are-dementia-friendly-communities-the-bestwecan-hope-for/ (Consulted 29 January 2016)

Pratchett, T. (2015). 'A butt of my own jokes', http://www.theguardian.com/books/2015/mar/15/a-butt-of-my-own-jokes-terrypratchetton-the-disease-that-finally-claimed-him accessed January 31st 2016

Roberts, H. Turner, S. Baines, S., Hatton, C. (2012) Advocacy by and for adults with learning disabilities in England. Improving Health and Lives: Learning Disabilities Observatory. https://www.ndti.org.uk/uploads/files/IHAL_2012-03_Advocacy.pdf (Consulted 27 February 2017).

Romero, B., \& Wenz, M. (2001). Self-maintenance therapy in Alzheimer's disease. Neuropsychological Rehabilitation, 11 (3-4): 333-355.

Sabat, S. R. (2014). A bio-psycho-social approach to dementia. Excellence in Dementia Care: Research into Practice, 2nd edition. M. Downs and B. Bowers. Maidenhead, UK, McGraw Hill: 107-122.

Sabat, S. R. (2008). A bio-psycho-social approach to dementia. Chapter 4, 71-84 in Excellence in Dementia Care: Research into Practice. M. Downs and B. Bowers (eds) . Maidenhead: Open University Press. 
Sabat, S. R. (2001). The Experience of Alzheimer's Disease. Life Through a Tangled Veil. Oxford: Blackwell.

Sabatello, M. and Schulze, M. eds. (2014) Human Rights and Disability Advocacy, Philadelphia, University of Pennsylvania Press.

Scully, J.L. (2012). The Convention on the Rights of Persons with Disabilities and cultural understandings of disability, in J Anderson and J Philips (eds) Disability and Universal Human Rights, Utrecht: Netherlands Institute of Human Rights, Chapter 4: 71-84

Saunders, P.A. (1998). 'My brain's on strike' - the construction of identity through memory accounts by dementia patients, Research on Aging 20(1) pp.65-90

Shakespeare T (1994) Cultural representation of disabled people: dustbins for disavowal? Disability and Society 9, 3: 249-264

Shakespeare, T. (2006). Disability Rights and Wrongs, London, Routledge.

Stephan, B. and C. Brayne (2010). Prevalence and projections of dementia. Excellence in Dementia Care: Research into Practice. M. Downs and B. Bowers. Berkshire, Open University Press: 9-34.

Swaffer, K. (2016). What the Hell Happened to My Brain? London: Jessica Kingsley Publishers.

Taylor, R. (2007). Alzheimer's from the Inside Out, Baltimore MD: Health Professions Press.

Taylor, R. (2011). The Voices of Dementia : http://www.gpli.org/images/dementia_journal.pdf accessed February 14th 2016.

Thomas C. (1999). Female Forms: experiencing and understanding disability, Buckingham, Open University Press. 
Thomas, C. (2007). Sociologies of Disability and Illness: contested ideas in disability studies and medical sociology, Basingstoke, Palgrave Macmillan.

Thomas, C. and Milligan, C., (2015). How can and should UK society adjust to dementia, York: Joseph Rowntree Foundation.

Wallcraft, J. and Bryant, M. (2003). The mental health service user movement in England, London, Sainsbury Centre for Mental Health.

Wherton, J.P, Monk A.F. (2008). Technological opportunities for supporting people with dementia who are living at home, International Journal of Human-Computer Studies 66: $571-586$

Whitman, L., ed. (2015). People with Dementia Speak Out, London: Jessica Kingsley Publishers.

World Health Organisation (2002). Towards a common language for functioning, disability and health: ICF, Geneva, World Health Organization. (http://www.who.int/classifications/icf/icfbeginnerCsguide.pdf?ua=1Consulted 28 April 2016)

World Health Organisation (2003). The Global Burden of Disease: A response to the need for comprehensive, consistent and comparable global information on diseases and injuries. Geneva: WHO.

World Health Organization (2011). World report on disability, Geneva, WHO.

World Health Organisation (2015) Global Action Against Dementia. WHO: Geneva

World Health Organization (2016). World report on ageing and health, Geneva, WHO.

Xie, J., Brayne, C. \& Matthews, F.E. (2008). Survival times in people with dementia: analysis from population based cohort study with 14 year follow-up. BMJ 336:258 
Zeilig, H. (2014). Dementia as a cultural metaphor. The Gerontologist 54(2): 258- 267.

Zeilig, H. (2015). What do we mean when we talk about dementia? Exploring cultural representations of “dementia”. Working with Older People 19(1): 12-20.

Zeisel, J. (2009). I'm Still Here: A Breakthrough Approach to Understanding Someone Living with Alzheimer's. New York: Penguin Group (USA). 